\title{
Does social capital enforce social distancing? The role of bridging and bonding social capital in the evolution of the pandemic
}

\author{
Vincenzo Alfano ${ }^{1,2}$ (D)
}

Received: 5 August 2021 / Accepted: 11 December 2021 / Published online: 27 January 2022

(c) Springer Nature Switzerland AG 2021

\begin{abstract}
By shaping the way people look at members of their networks as well as strangers, social capital affects the behavior of a population during a pandemic. Over the course of 2020, various countries implemented non-pharmaceutical interventions (NPI), imposing restrictions that were difficult to enforce (due to the scale of the policies) in order to protect the public from the threat of COVID-19. This is an interesting quasi-experimental setting in which to test the compliance of populations with different levels of social capital with government suggestions and prescriptions. With the help of European Social Survey data, and the John Hopkins University dataset on the spread of COVID-19 around the world, the present work aims to test the impact within a sample of European countries with different social capital stocks on the spread of coronavirus. The results show that countries with higher social capital have fewer COVID-19 cases, ceteris paribus for NPI. This is especially true if this capital is of the bonding kind.
\end{abstract}

Keywords Non pharmaceutical intervention · Social capital · Trust · COVID-19

JEL classification $\mathrm{D} 62 \cdot \mathrm{H} 12 \cdot \mathrm{I} 18$

Man is by nature a political animal. -Aristotle

Vincenzo Alfano

valfano@wiut.uz

1 Department of Economics, Westminster International University in Tashkent, Tashkent, Uzbekistan

2 Center for Economic Studies-CESifo, Munich, Germany 


\section{Introduction}

2020 will be a year long remembered for having been the first of a pandemic that, about a century after the last one, affected the entire planet, forcing more or less every person on earth to adopt significant changes in his or her everyday life. Some of the wealthiest and most developed countries in the world discovered their fragility when faced with an invisible enemy that was difficult to keep outside their borders. The citizens of Western countries in particular had to learn to cope and live with non-pharmaceutical interventions (NPI). These are a set of policies aimed at reducing the possibility of contagion that, certainly in spirit, and often also in practice, are very similar to Middle Age remedies for fighting the plague. Indeed, many contemporary governments have taken recourse to policies similar to those invented by the Republic of Venice in the seventeenth century, when the first public authorities established specifically to safeguard public health adopted resolutions to fight the scourge of the plague (Alfano \& Sgobbi, 2021). Stay-at-home orders and imposed self-isolation have taken the place of lockdowns and quarantine, to avoid the spread of COVID-19. Several remedies aimed at increasing social distancing have been imposed by public authorities in order to reduce opportunities of contagion, and thus to flatten the curve of infections. To this set of policies belong remedies such as stay-at-home orders, bans on public gatherings, the closure of schools, and more generally all the social distance remedies that were adopted by public authorities in order to contain the diffusion of the virus (Centers for Disease Control and Prevention, 2007).

Over the course of 2020 it became clear that the evolution of COVID-19 infections is influenced by the seasons (Smith et al., 2020), and thus that the northern and southern hemispheres exhibit counter trends, and are difficult to compare. Taking into account this difference by focusing on countries in a specific area (and more specifically on the climatically more homogeneous region of Europe), it might seem at first glance that state reactions to the threat have been largely homogeneous.

Nonetheless, if we look at the varying diffusion rates of COVID-19 in the different countries, anecdotal evidence suggests that the effectiveness of such remedies varied greatly from country to country. This is further confirmed by recent empirical studies that highlighted fear of the future, behavioral change, and systematically negative expectations regarding the future during the first COVID-19 wave (Bogliacino et al., 2021; Codagnone et al., 2021).

One reason to explain the heterogeneity of these policies' effectiveness is the peculiarity of NPIs compared to other kinds of policy. Since these are aimed at the entire population of a country, in Western democracies, which have certain standards regarding civil liberties and democracy, it is difficult for public authorities to enforce the respect of these restrictions with the use of force, given the scale of the phenomenon to keep under control.

Indeed, it is easy to understand that the vast majority of the population is the target of lockdowns and social distancing measures, and that an important degree of voluntary compliance by the population is needed for these NPIs to work, 
since law-enforcement authorities do not, and probably may never have enough resources at their disposal to control the behavior of the entire population with success. Some NPIs oblige people to restrict certain behavior to private space (for instance, Italy, France and Germany adopted restrictions on the number of people that may gather in a private house); others, by their very nature, are more or less unenforceable, and depend purely on people's good will (such as the restriction imposed in Italy by the decree of 12 March 2021 forbidding citizens from visiting friends and relatives "more than once" per day, a prescription that it is difficult to imagine public authorities having the ability to actually control). From all this it seems possible to conclude that, since NPIs are potentially a (very) restrictive policy that significantly affects citizens' everyday behavior, and since they must be respected mainly on a voluntary basis, there is a space for the specific characteristics of a country to play an important role in the effectiveness of these NPIs. Among these characteristics, social capital seems to be a particularly interesting variable to test.

By influencing the way people look both at other people belonging to their networks, and at strangers, it is very likely that social capital could constitute a determinant that affects the evolution of a pandemic and compliance with NPIs. Moreover, social capital also influences the way members of a given community have access to, and interact with, their different networks. It is easy to understand how this has an impact on the spread of an airborne disease such as COVID-19, and consequently on the efficacy of NPIs. It is important to highlight that social capital may have an impact on the evolution of the epidemic through several channels. The most obvious one, especially during the first wave when neither cures nor a vaccine was available, is through nudging people to respect social distancing, either in compliance with government NPIs, or by favoring the efficacy of other measures, such as common sense and World Health Organization suggestions. But there is more: another possible channel through which social capital could affect the trend of COVID-19 infections is by influencing everyday behavior that favors the spread of the virus, such as the decision to use public rather than private transport, which has been suggested to have played an important role in the spread of the virus (Alfano et al., 2021).

Previous literature, with reference to many different fields, from genetically modified organisms (Kim, 2011) to nuclear energy (Jasanoff \& Kim, 2009), suggests that political culture needs to be taken seriously in order to ensure the effectiveness of policies. Indeed, as explained, the manner in which people respect NPIs may also depend on the way they look at their communities, on the degree of trust and reciprocity they have in others, and on the degree of confidence they have in the authorities. However, little is known about the effect of trust on compliance with health and safety rules (Bargain \& Aminjonov, 2020). The COVID-19 pandemic seems to be the perfect setting in which to study the relationship between social capital and policy compliance, since it has been suggested that the COVID-19 crisis can be seen as a "global, and (mostly) simultaneous test of the behavioral implications arising from this confidence" (Chan et al., 2020: p. 1).

The overall purpose of this study is to contribute to a better understanding of the role social capital plays in the diffusion of COVID-19. 
More specifically, this study aims to examine, from a European cross-country perspective, whether and how social capital is related to a lower spread of COVID19, ceteris paribus for the NPIs enforced. The research question of the present work may therefore be stated as follows: "What role does social capital play in the containment of COVID-19 infections?".

We consider this to be an important research question for at least two reasons. First, it is interesting to assess the impact of social capital on the spread of COVID19 since the coronavirus pandemic remains a major threat for a large part of the global population, and thus research devoted to understanding the impact of sociocultural characteristics on NPI effectiveness is useful as a means to help policymakers design better policy and estimate the impact of such policies, aside from forecasting the trend of contagion. The literature already has several pieces of research devoted to assessing the impact of NPIs (Alfano \& Ercolano, 2020b; Alfano et al., 2021); it now seems important to also evaluate whether there is an effect on the efficiency of the policy due to the population on which it is applied. Moreover, epidemics and global pandemics are predicted to be a significant and continuing threat in the next few years (Adamson et al., 2021; Hotez, 2021; Simpson et al., 2020), and thus research devoted to understanding the impact of social capital on NPI effectiveness seems to be destined to become increasingly useful and necessary in the near future. We expect social capital to be a determinant of this relationship, since it influences the way networks of people are constructed, and the way people behave within and between these networks.

Second, the COVID-19 pandemic and different populations' NPI compliance provide a very interesting quasi-experimental setting in which we may understand more generally the impact of social capital on the degree of people's respect for policies. One of the major shortcomings of the existing literature addressing this area is that it is very difficult to assess how many people have complied with a given policy, due to the intrinsic resistance of people to admit they have infringed the law, which typically hampers the usefulness of survey data in such research. Similarly, it is very difficult to assess levels of law compliance among the general population. While researchers in the field have found a number of creative ways to overcome this problem and find proxies for the degree of law compliance among the population, it seems that the COVID-19 crisis offers an interesting setting in this regard, given that the trend of the contagion is a good proxy for the degree of compliance with NPIs aimed at halting the spread of disease in the entire population of a given country.

Finally, the chance to observe this relationship in a cross-country perspective, presented by the exogenous shock created by the pandemic, allows us to obtain estimates that we may generalize with more confidence. This setting enables us to have better estimations, and to avoid biases due to omitted variables or unobserved shocks impacting this relationship, which may easily constitute a weakness and an empirical challenge that would be difficult to overcome in a single country study.

The remainder of this work is organized as follows. The next section reviews the relevant literature and formulates the research hypotheses. Section three presents the empirical strategy and the data used to test this relationship, while section four shows the relative results. The last section concludes. 


\section{Relevant literature and research hypotheses}

As highlighted by Ferragina and Arrigoni (2016), the concept of social capital was brought to the field of social sciences through the work of Hanifan (1916), first, and later Jacobs (1961). These scholars argued that social capital could be accumulated or destroyed according to the appropriateness of the "social investments" made by communities. The theory was advanced by Bourdieu (1980), who used the concept as a heuristic tool to complement the analysis of class stratification. Meanwhile, Coleman $(1988,1990)$ employed social capital theory to associate social relations with the utility function of individuals.

This intense scholarly debate has heavily influenced the connotation of the concept (Ferragina, 2010). Symptomatic of this was the re-elaboration of old theories with intensive data analysis that characterized the field at the end of the twentieth century. Indeed, decades later their formulation, in the works of Putnam (1993, 1995), continued to attract a great deal of attention. Possibly this happened because they are "a valuable exercise in refining the explanatory power of the social capital concept" (Ferragina, 2010: p. 79), making a case for measuring the impact of "cultural and social aspects" on institutional performance, following the same path of analysis as Banfield, 1958 (Ferragina, 2009, 2011)

While several definitions have been proposed (for an overview of the most influential, see Adler \& Kwon, 2002), social capital is often defined as the capital that is accumulated by individuals and groups through their social interactions (Putnam, 1995). It can be used to smooth cooperation among people and foster collective action (Putnam, 1995).

Putnam's (1993) notion possibly represents the vertex in the social capital theory parabola. For Ferragina and Arrigoni (2016) it is the "critical juncture" with which the academic concept acquires relevance in political discussion.

This concept was soon applied empirically in different domains, for instance in relation to economic, educational and ethical outcomes. It is nonetheless important to remember that, according to Putnam himself (2000, p. 326), in none of these domains "is the importance of social connectedness so well established as in the case of health and well-being". Previous findings in this field argue that social capital has an impact on reduced mortality (Kawashi et al., 1997), higher perceptions of well-being (Helliwell, 2002), better mental and subjective health (Kawachi et al., 1999; Kawachi \& Berkman, 2001; Rose, 2000), and a lower tendency to depression or loneliness (Penninx et al., 1999). It has also been suggested that there are theoretical reasons why social capital should enforce obedience of the police (Hawdon, 2008) and police legitimacy (Tyler \& Jackson, 2014).

But what is social capital? Over the years several qualitative differences in social capital have been proposed, and there are thus various empirical operationalizations of the concept. One of the most widely used distinctions in the literature is that between bonding and bridging social capital.

Putnam (2000: p. 22) defined bonding social capital as "inward looking [networks that] tend to reinforce exclusive identities and homogeneous groups". The concept suggests strong ties and within-group cohesion; bonding is fundamentally 
characterized by a tightening of relationships and networks within the group, while simultaneously excluding non-members (Granovetter, 1973). This concept has also been related to previous qualitative research that identified strong family ties that hampered societal development in Southern Italy (Banfield, 1958).

It has been suggested (Olson, 1982) that high stock of this kind of social capital in the population leads to interest groups that create benefits for members, which at the same time impose disproportionate costs on the rest of society. Thus, bonding social capital, while favoring network members (often constituted by the original family), may easily have a negative total effect on society as a whole. These kinds of groups, following a distinction made by Knack and Keefer (1997), and already used in the literature by Beugelsdijk and Smulders (2009), Cortinovis et al. (2017), and Muringani et al. (2021), can be defined as Olson groups. High stocks of bonding social capital within a delimited place are thus likely to result in rent-seeking, insider-outsider problems, clientelism, and nepotistic practices (Crescenzi et al., 2013; Crescenzi \& Gagliardi, 2015; Farole et al., 2011; Rodriguez-Pose \& Storper, 2006; Storper, 2005, 2013).

It has also been suggested that, at least in the case of Italy, bonding social capital has played a role in the superior performance of some provinces in reducing the spread of COVID-19. According to Alfano and Ercolano (2020a), this happens either because bonding social capital leads to an increase in the willingness to protect the elderly members of a family, or because it implies distrust in people outside the family network.

Another kind of social capital is the 'bridging' variety. This is a concept that refers to the existence of open networks that connect heterogeneous groups (Antonietti \& Boschma, 2018; Beugelsdijk \& Smulders, 2009; Boschma, 2005; Cortinovis et al., 2017; Crescenzi \& Gagliardi, 2015; Rodriguez-Pose \& Storper, 2006; Storper, 2005, 2013). With reference to this kind of social capital, we may define networks characterized by this capital as "Putnam groups".

Following Putnam's (1993) argument, participation in civic or voluntary associations, such as educational and cultural groups, leads to positive social and economic outcomes and is a proxy of bridging social capital.

It is beyond the scope of this review to summarize the vast literature on the effects of bridging social capital. It is nonetheless possible to say that this form of social capital is generally considered to have positive effects on socio-economic outcomes (Beugelsdijk \& Smulders, 2009; Farole et al., 2011; Putnam, 2000; Rodriguez-Pose \& Storper, 2006; Storper, 2005, 2013).

The literature has compared the effects of belonging to the two groups. Knack and Keefer (1997) found that while belonging to an Olson group has no effect on growth or investment, Putnam groups appear to harm investment; Knack (2003), on the other hand, in a cross-country analysis finds scant support for Olson's view of the impact of groups, and mixed support for the Putnam perspective. More recently, Degli Antoni and Grimalda (2016) found that Putnam group members display more generalized trust, while the opposite is true for Olson groups. On the other hand, examining trustworthy behavior, the opposite is true: members of Olson groups are more trustworthy than non-members, and vice-versa. 
While some of the literature has perceived social capital as a miracle concept that is able to provide answers to a range of phenomena beyond an economic lens (Poder, 2011), it is important to recognize that it has also been widely criticized, mostly for its ambiguity and variability. Some authors describe the concept as "fundamentally flawed" (Fine, 2002). It has also been claimed that it is impossible to measure social capital. Haynes (2009) suggests that problems of circularity make it a tautology, and that it is highly context dependent. Other scholars stress the fact that while some aspects of it are objective, others are subjective, and that rather than a proper socialization process, there are a number of circles to which one might belong (Bourdieu, 1986; McShane et al., 2016).

An important strand of the literature does not consider bonding and bridging social capital to be mutually exclusive stocks; on the contrary, the two political culture characteristics interact with each other, and their different mixes produce different outcomes. According to Rodriguez-Pose and Storper (2006), and Storper (2005, 2013), high levels of both produce better socio-economic outcomes, whereas low bridging and high bonding results in so-called "amoral familism". The notion, made popular by the work of Banfield (1958), is based on the idea that prioritizing present orientation over future planning is the distinctive character of backwardness (Ferragina, 2009). This implies that cultural factors are far more important than socioeconomic factors in understanding backward contexts (especially rural ones). High bridging and low bonding social capital results in a lack of sanctions to ensure common expectations, and low levels of both lead to "amoral individualism". Sabatini (2008), who also includes a third, "linking" dimension of social capital, finds that bonding social capital negatively affects human development but significantly fosters the quality of life, while bridging social capital has a significantly negative effect on human development.

Nonetheless, even if it has been widely studied in the last century, surprisingly it remains unclear what kinds of networks exert a positive effect on the different dimensions of development (Sabatini, 2008).

There are reasons to believe that social capital may play an important role with specific reference to the COVID-19 crisis. Social capital affects vertical and horizontal relations within a community that are likely to affect the spread of contagion in the society. Moreover, compliance with imposed restrictions is also likely to be affected by social capital. Different levels of obedience, and different network shapes and degrees of belonging, may easily affect the way citizens follow prescribed NPIs. Finally, it is important to highlight that it has already been suggested that bridging social capital may have reduced positive effects in halting the spread of COVID-19 when compared to bonding social capital, at least in the case of Italy (Alfano \& Ercolano, 2020a).

Based on this brief overview of the literature on social capital, it is possible to examine the direct effects of each type on the spread of COVID-19, ceteris paribus for NPIs and other variables that may affect this relationship. Previous empirical findings noted that social capital is correlated with a reduction in mobility after lockdown was enforced in the US (Borgonovi \& Andrieu, 2020), and that bonding social capital has a higher impact than bridging social capital on the reduction in COVID-19 cases once a lockdown is enforced (Alfano \& Ercolano, 2020a); so far, 
however, to the best of our knowledge, no contribution has examined this relationship in a cross-country perspective. We expect to confirm the finding in this context as well. Therefore, we test the following hypothesis:

H1 Countries with a higher stock of bonding (bridging) social capital have higher (lower) decreases in COVID-19 cases than countries with a higher stock of bridging (bonding) social capital, assuming parity of NPIs under enforcement, and all other relevant conditions.

\section{Research strategy, methodology and data}

Previous contributions have been devoted to empirically assessing the impact of a specific NPI (regarding lockdowns: Alfano \& Ercolano, 2020b; regarding school closures: Alfano \& Ercolano, 2020c; Alfano et al., 2021) on new COVID-19 cases, in a cross-country perspective. The empirical strategy employed in this case is the use of so-called fixed effects estimations. It is widely recognized in the econometric literature that fixed effects models have an advantage over random effects models when analyzing panel data because they control for all level 2 characteristics, whether measured or unmeasured (Allison, 2009; Halaby, 2004; Wooldridge, 2010). This is especially important when modeling a new phenomenon that is not entirely clear yet, in which time-invariant characteristics (such as demographic composition, population density, characteristics of the healthcare system, and more generally all the characteristics that do not change over the time span analyzed) are likely to play a role. In this way, the empirical estimation implicitly controls for all the variables that do not (significantly) change at observation in the time span analyzed, and which may influence COVID-19 diffusion.

This advantage is at the same time the major drawback of these kinds of models. What limits them is their inability to estimate the impact of a variable that does not vary both within the level of observation and the time span. Previous contributions proposed to overcome this issue by dividing the sample by quantiles of the variable of interest, and estimating the impact on different subsamples, before proceeding to a comparison of the betas (Alfano \& Ercolano, 2020a, 2021a, 2021b). This empirical strategy has two principal limitations: the first is comparing betas that have been estimated in different samples, which may of course be affected by different biases and errors; the second is that dividing the sample by quantiles of one variable means also dividing it by all the variables that are highly correlated with it, creating uncertainty in the identification of the effect.

To circumvent this disadvantage, a different strategy may be employed. It has been proposed that within effects can be estimated in random-effects models (Allison, 2009; Neuhaus \& Kalbfleisch, 1998; Rabe-Hesketh \& Skrondal, 2008; Raudenbush, 1989; Wooldridge, 2010). Sometimes these models are also called hybrid models. As suggested by Schunck (2013), this approach offers a number of advantages: among them, this empirical approach allows the inclusion of random slopes, enabling the effects of time-invariant variables to vary between clusters, and thus to be estimated. In other words, via this empirical approach we may estimate the 
impact of an independent time-invariant variable on a dependent variable, in the context of a fixed effects estimation. This means that we may have the advantages of a fixed effects model, in terms of controlling for observed and unobserved characteristics, and at the same time we are able to test the impact on this relationship of a time-invariant variant (which is typically the case for social capital).

In more formal terms, we may model the research question through the following equation:

$$
\Delta i_{c t}=\alpha+\beta_{1}\left(i_{c t-1}-\overline{i_{c}}\right)+\beta_{2} \overline{i_{c}}+\beta_{3}\left(\operatorname{Str}_{c t-28}-\overline{\operatorname{Str}_{c}}\right)+\beta_{4} \overline{\operatorname{Str}_{c}}+\beta_{5} \operatorname{SocCap}_{c}+\beta_{6} \mathrm{~T}+\varepsilon
$$

where the dependent variable $\Delta i$ is new COVID-19 cases at time $t$, with respect to $t$ - 1 , in country $c$. This, following the principal literature on the theme (Alfano \& Ercolano, 2020b), is modeled as a function of the total infections in country $c$ on the previous day $\left(i_{t-1}\right)$, decomposed into its within country part (the difference from the country mean of each observation $i_{c t-1}-\overline{i_{c}}$ ) and between country (each country mean, $\bar{i}_{c}$ ); and as a function of Str, an index measuring the level of stringency of the different NPIs that are in place for at least twenty eight days (to allow them to have an effect on the reporting of new COVID-19 cases: this will be explained in more detail below), once again decomposed into its within and between effects. Furthermore, the equation includes SocCap, a time-invariant variable that proxies each of the social capital operationalizations useful for testing our hypotheses, and $T$, a matrix of monthly fixed effects, included to control for any exogenous effect that may have affected the relationship during a month (such as a change in the testing protocols).

This approach, which is innovative even though it is based on those already adopted by the literature (Alfano \& Ercolano, 2020a, 2020b), allows us to estimate (in $\beta_{5}$ ) the impact of social capital on new COVID-19 cases, taking into account both the specific evolution of the contagion in a country (with regard to the total cases on the previous day) and to the level of stringency of the NPIs implemented in the period. Thus, on the assumption that NPIs are designed to have an important effect in curbing the infection curve, and that they are one of the main causes of a reduction in cases, the impact of SocCap on $\Delta i$ measures the impact of social capital on the efficiency of these kinds of policies (since the trend in cases should be due principally to NPIs), and other social distancing measures.

Of course, as already stated, other mechanisms may affect this relationship, such as the impact of social capital on personal preferences (for instance the willingness to use public rather than private means of transportation), or increased attention in protecting the elderly members of one's family.

In order to estimate Eq. (1), we need the daily number of COVID-19 cases in a sample of countries, daily data on the stringency of NPIs, and an operationalization of social capital. Data for operationalization of the first two variables are gathered from the Oxford COVID-19 Government Response Tracker dataset (henceforth OxCGRT, Hale et al., 2020a), compiled from publicly available information by a cross-disciplinary Oxford University team of academics and students from every part of the world, led by the Blavatnik School of Government (Hale et al., 2020b). 
We use the latest version available at the time of writing, namely the edition of 26 March 2021. It offers a country-by-country daily estimation of COVID-19 cases. In order to avoid biased estimations due to the variance of the spread of COVID-19, as well as the differences in testing strategies and reporting, we focused on the first wave of the pandemic, from 1 January 2020 to 31 August 2020. From this source we computed New cases pm, the operationalization of $\Delta i$ in Eq. (1), as the first difference between the COVID-19 cases of day $i_{t}$ and $i_{t-1}$ for each country $c$, divided by the population of country $c$ (data from World Bank dataset in 2019), and multiplied by $1,000,000$, to obtain the number of cases per each million inhabitants. From the same source we also computed YCases pm, the operationalization of $i_{c t-1}$, which is equal to the absolute value of cases at $t-1$, divided once again by the population of country $c$ and multiplied by $1,000,000$, in order to obtain a per million variable.

We expect the main source of reduction in New Cases pm to be the implementation of NPIs (although, as discussed above, we cannot exclude in line of principle that social capital also has an effect on the trend of cases through other channels, due to its impact on personal behavior, such as a greater concern for others' well-being). To operationalize the stringency of NPI measures on a daily basis, we relied on the same source (Hale et al., 2020a). OxCGRT also offers the Oxford Stringency Index, a measure of the different policies implemented in order to fight COVID-19 in each country $c$ for each day $t$. It is calculated as the sum of several different sub-indexes, then rescaled as a single variable on a 0-100 base. We used this index, labeled Str, as a proxy of all the NPIs that may affect the dependent variable New Cases pm. More precisely, this index takes into account: workplace closures, cancellation of public events, restrictions on the size of gatherings, closures of public transportation, home confinement orders, and restrictions on internal and international travel. All things considered, this seems to be a very good proxy for taking into account and controlling for all the NPIs that (if respected) should affect the outbreak of the coronavirus. In the estimation, this variable is lagged, given that NPIs need some time to show results. We measure the spread of COVID-19, and consequently the efficacy of NPIs, through the daily count of people who tested positive. For testing to take place it was very likely that one would need to exhibit some symptoms first, and this was even truer during the first wave (which we are analyzing). The literature suggests that $97.5 \%$ of those who develop symptoms of COVID-19 do so within 11.5 days of infection, with a 95\% confidence interval of between 8.2 and 15.6 days (Lauer et al., 2020). After developing symptoms, especially during the first wave, it is very likely that more time is needed to get tested, to obtain the results of these tests, and finally to appear in the official statistics. For this reason, considering also the lag for an impact from lockdown to be seen, as suggested by previous literature (Alfano \& Ercolano, 2020b), we chose to delay the variable Str by four weeks (28 days), in order to measure the impact of Str on people that were not likely to test positive after the NPI was enforced. In other words, the value of Str in country $c$ when $t=29$ is equal to the value of the Oxford Stringency index for country $c$ on day $t$. This is to avoid referring to a change in New cases pm that is unlikely to be due to the NPI.

Finally, there is the operationalization of SocCap. In order to test H1 empirically, we computed a country average of certain social capital characteristics, using as our main source the last available edition of the European Value Study (EVS), which 
was carried out in 2017 (EVS, 2020). This is a survey that collects individual level data through interviews conducted in several European countries, and is widely used in the social sciences. Please note that since the interviews in question date from 2017, the social capital proxies are prior to the COVID-19 crisis, and hence are not affected by the way national governments managed the pandemic. There is thus no risk of reverse causality. At the same time, previous findings in the literature suggest that cultural traits persist for surprisingly long periods of time at a national level (Bjørnskov, 2007). Several operationalizations of SocCap have been calculated from the EVS (2020).

First, following Knack and Keefer (1997), we operationalize these two concepts by adopting the distinction already used in the literature by, Beugelsdijk and Smulders (2009), Cortinovis et al. (2017), and Muringani et al. (2021). This consists of classifying different types of organizations into either "Olson" groups, which exhibit rent-seeking behavior, or "Putnam" groups, which offer openness and benefit for non-members.

Accordingly, we classify participation declared by respondents in EVS (2020) as follows: "Olson" type groups include trade unions, political parties, professional associations, and consumer organizations; "Putnam" type groups include participation in religious organizations, cultural activities groups, environmental groups, sports or recreation groups, charitable or humanitarian groups, and self-help groups. From these data we compute the average country stock of social capital of each type in two different ways.

First, we calculated a measure of bonding social capital by computing Bonding, a variable that represents the share of respondents in each country that declare they belong to at least one "Olson" group, and similarly Bridging, a proxy variable for this kind of social capital, by computing the share of respondents in each country that declare they belong to at least one "Putnam" group (this operationalization is also weighted using the statistical weights provided by EVS, to maintain the sample's statistical representativeness). Second, given that the notion that active participation is necessary for the formation of social capital has been questioned, with some studies suggesting that greater attention be paid to the importance of multiple affiliations within associations (Wollebaek \& Selle, 2002), we also compute Bonding-Cont., by computing for each respondent the share of "Olson" groups she/he belongs to (for instance, if someone belongs to a trade union and a political party, she will have a score of $2 / 4$, and thus of 0.5 ), and then calculating the country average of all the respondents (once again using statistical weights). Bridging-Cont. is determined in a similar way, computing for each respondent the share of "Putnam" groups she/he belongs to, and then collapsing these values into country averages corrected for statistical weights.

We thus obtained two operationalizations for each kind of social capital, one that simply considers belonging to at least one group, and the other which also gives weight to how many of these groups the respondent belongs to. Figures 1 and 2 present a heat map of the distribution of social capital in the different countries studied, for each of the operationalizations. Moreover, Cronbach's alpha statistics, presented in Table 1, suggest that this pair of variables is an internally consistent operationalization of the concept. 


\section{Bridging social capital}

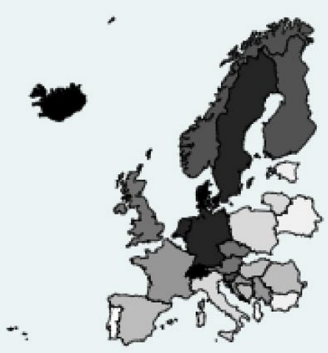

Bonding social capital

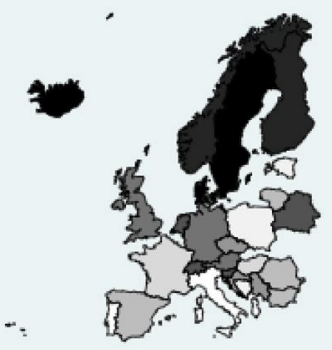

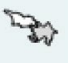

Fig. 1 Heat map of bridging and bonding social capital in the country studied

\section{Bridging (cont.) social capital}

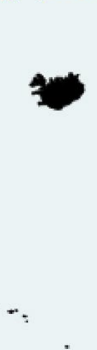

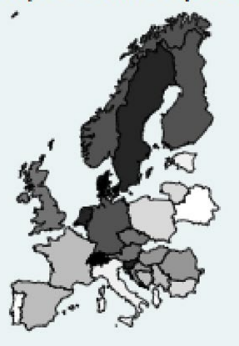

\section{Bonding (cont.) social capital}

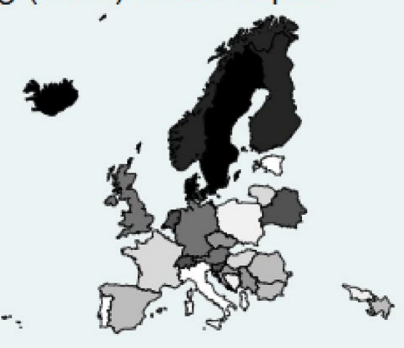

Fig. 2 Heat map of bridging and bonding social capital (continuous operationalization) in the countries studied

Table 1 Cronbach's alpha statistic for bonding and bridging social capital operationalizations

\begin{tabular}{lllllll}
\hline Variable & Obs & Sign & $\begin{array}{l}\text { Item-test cor- } \\
\text { relation }\end{array}$ & $\begin{array}{l}\text { Item-rest cor- } \\
\text { relation }\end{array}$ & $\begin{array}{l}\text { Average interitem } \\
\text { covariance }\end{array}$ & Alpha \\
\hline Bonding & 7320 & + & 0.9325 & 0.8545 & 0.0116192 & 0.7606 \\
Bridging & 7320 & + & 0.9608 & 0.8789 & 0.0088926 & 0.8321 \\
Bonding-Cont & 7320 & + & 0.9330 & 0.9149 & 0.0216053 & 0.8601 \\
Bridging_Cont & 7320 & + & 0.9580 & 0.9425 & 0.0192565 & 0.8269 \\
Test scale & & & & & 0.0153434 & 0.8629 \\
\hline
\end{tabular}


Table 2 Hausman test for fixed versus random effects, baseline model
Ho: difference in coefficients not systematic

$\operatorname{chi} 2(1)=(b-B)^{\prime}\left[\left(V_{\mathrm{b}}-V_{\mathrm{B}}\right)^{(-1)}\right](b-B)=84.97$

Prob $>$ chi $2=0.0000$

All this leads to the creation of a panel dataset composed of 30 different countries (all those included in EVS, 2020 ${ }^{1}$ ) observed for 244 days (between 1 January 2020 and 31 August 2020). Having chosen to lag Str (in order to allow the NPIs to have an effect on New Cases pm) by 28 days, 28 observations per country are lost, leaving 6480 observations in the regressions (30 countries multiplied by 216 days). The hybrid estimation also allows us to implicitly test for equivalence of within and between estimates by comparing coefficients of within and between variables (the so-called augmented regression test, Jones et al., 2007, p. 217). This has been used as an alternative to a Hausman specification test (Baltagi, 2008, p. 73): nonetheless we provided a Hausman test in any case, which is presented in Table 2, and suggests the appropriateness of a fixed effects estimation. Furthermore, descriptive statistics of all the variables used in the analysis are presented in Table 3.

\section{Results}

Results are presented in Table 4. All the coefficients were estimated through F-GLS Hybrid Models, with standard errors clustered at a country level. Figure 3 summarizes the results, and shows the coefficient of greatest interest of the regression in the same picture, for an easier comparison of the value and the confidence intervals.

First of all, we should note that the coefficient of the YCases pm variable, in all its specifications, is positive and statistically significant. This suggests, as we might expect, given what we know about the exponential nature of COVID-19, and also as highlighted by previous literature with regard to the first wave (Alfano \& Ercolano, 2020b), that the more cases there were yesterday, the more COVID-19 cases there will be today, on average.

Also of interest is the coefficient of the Str variable (lagged by 28 days). It is negative and statistically significant, suggesting that, after 28 days, it is possible, on average, to see a negative impact of the stringency measures on the evolution of COVID-19 cases.

Bonding and bridging social capital are often presented as dichotomous, alternative concepts in the literature. This may lead people to expect regions with a high level of bridging social capital to have low levels of bonding social capital, and vice versa (Bürcher \& Mayer, 2018). It is important to highlight that this is not

\footnotetext{
1 These countries are: Albania, Austria, Azerbaijan, Belarus, Bosnia and Herzegovina, Bulgaria, Croatia, the Czech Republic, Denmark, Estonia, Finland, France, Georgia, Germany, Hungary, Iceland, Italy, Lithuania, the Netherlands, Norway, Poland, Portugal, Romania, Serbia, Slovak Republic, Slovenia, Spain, Sweden, Switzerland, and the United Kingdom.
} 


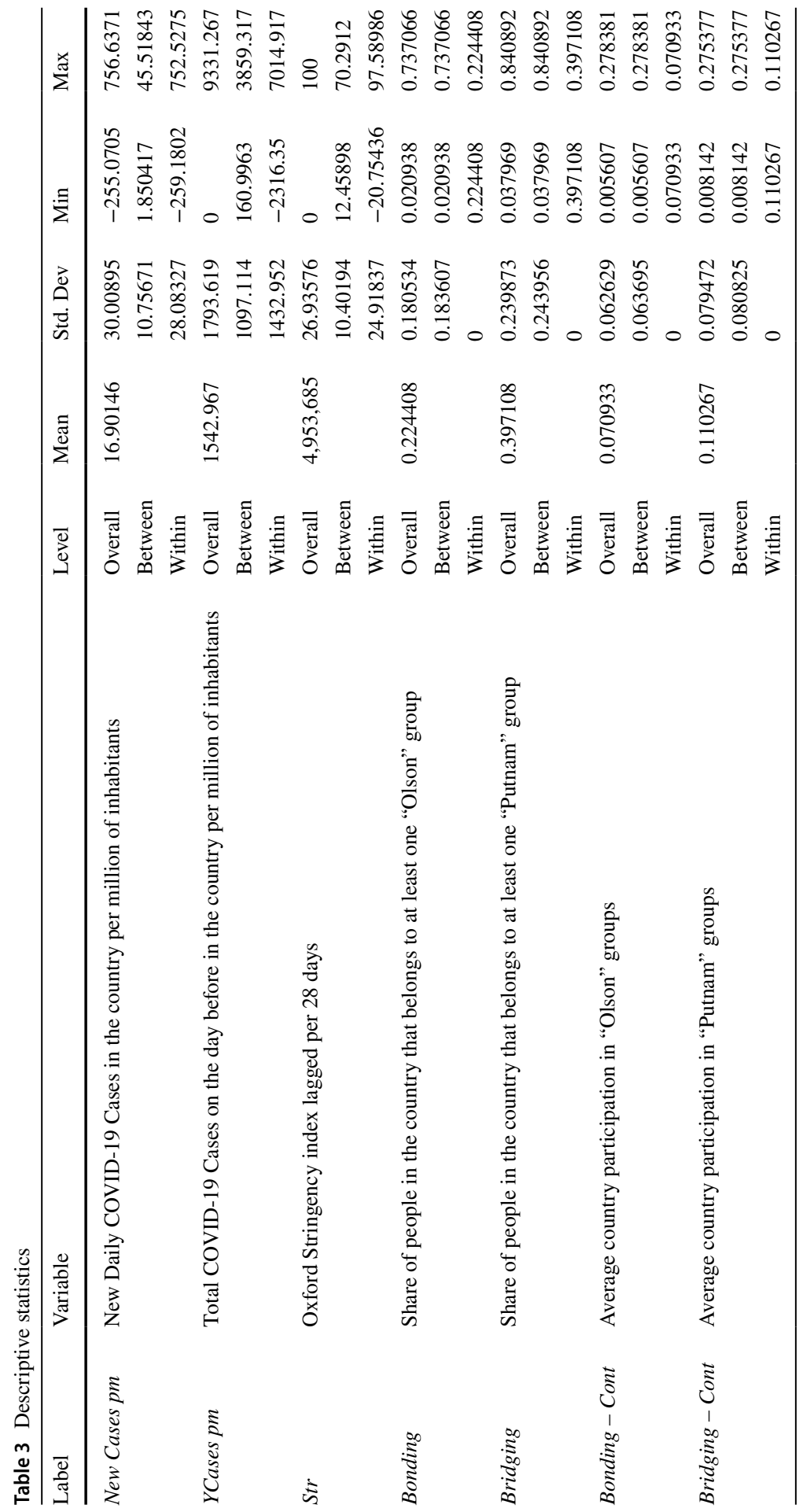


Table 4 F-GLS hybrid model bonding and bridging

\begin{tabular}{|c|c|c|c|c|}
\hline & (1) & (2) & (3) & (4) \\
\hline & New cases pm & New cases pm & New cases pm & New cases pm \\
\hline \multirow[t]{2}{*}{ YCases pm_within } & $0.00253 *$ & $0.00253 *$ & $0.00253 *$ & $0.00253 *$ \\
\hline & $(1.83)$ & $(1.83)$ & $(1.83)$ & $(1.83)$ \\
\hline \multirow[t]{2}{*}{ YCases pm_between } & $0.0103 * * *$ & $0.0100 * * *$ & $0.0104 * * *$ & $0.0101 * * *$ \\
\hline & $(12.15)$ & $(12.42)$ & (12.18) & $(12.61)$ \\
\hline \multirow[t]{2}{*}{ L28.Str_within } & $-0.206^{*}$ & $-0.206^{*}$ & $-0.206^{*}$ & $-0.206^{*}$ \\
\hline & $(-1.70)$ & $(-1.70)$ & $(-1.70)$ & $(-1.70)$ \\
\hline \multirow[t]{2}{*}{ L28.Str_between } & 0.0110 & 0.0623 & 0.0189 & 0.0610 \\
\hline & $(0.12)$ & $(0.83)$ & $(0.22)$ & $(0.84)$ \\
\hline \multirow[t]{2}{*}{ Bonding } & $-10.63 * *$ & & & \\
\hline & $(-2.13)$ & & & \\
\hline \multirow[t]{2}{*}{ Bridging } & & $-7.383 * * *$ & & \\
\hline & & $(-2.83)$ & & \\
\hline \multirow[t]{2}{*}{ Bonding-cont } & & & $-33.16^{* *}$ & \\
\hline & & & $(-2.43)$ & \\
\hline \multirow[t]{2}{*}{ Bridging-cont } & & & & $-24.48 * * *$ \\
\hline & & & & $(-3.01)$ \\
\hline Monthly fix effects & YES & YES & YES & YES \\
\hline \multirow[t]{2}{*}{ Constant } & $-17.82 * * *$ & $-19.14 * * *$ & $-18.37 * * *$ & $-19.41 * * *$ \\
\hline & $(-3.57)$ & $(-3.54)$ & $(-3.63)$ & $(-3.50)$ \\
\hline Observations & 6480 & 6480 & 6480 & 6480 \\
\hline
\end{tabular}

$t$ statistics in parentheses

$* p<0.1, * * p<0.05, * * * p<0.01$

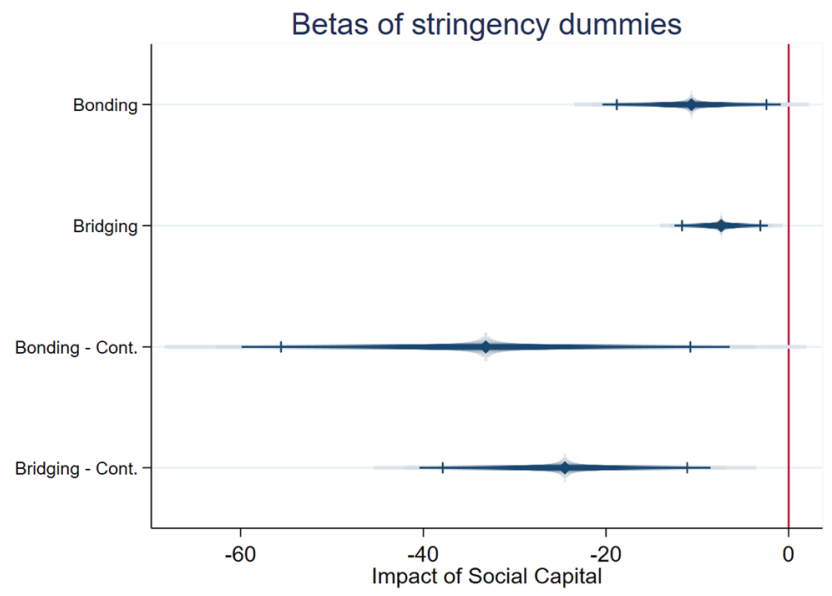

Fig. 3 Impacts on New Cases pm of Social Capital variables. Betas estimated in separate regressions and presented together to permit easier comparison. Lines and lighter colors represent $95 \%$ and $90 \%$ confidence intervals 
necessarily the case, as countries may have either high or low levels of both forms of social capital (Muringani et al., 2021). Indeed, empirical evidence suggests that the two forms often go together.

For these reasons, in order to test $\mathrm{H} 1$, we should look at the value of the betas of bonding and bridging social capital, and also compare the coefficients of these variables, in both their operationalizations. If we look at Table 4, both variables present a negative coefficient in both operationalizations (i.e., the SocCap variable has a negative coefficient in specifications 4.1, 4.2, 4.3 and 4.4). We may therefore state that a first finding of this research is that higher stocks of social capital, whether of the bonding or of the bridging kind, are related to a reduction in New cases pm, and consequently to better efficiency of NPIs (at least if one assumes that during the first wave of the pandemic, in the absence of cures or vaccines, compliance with NPIs was the main causal factor in reducing the spread of COVID-19; of course, as already stated, we cannot exclude possible alternative mechanisms through which social capital affects the contagion dynamic). Hence, a higher level of bonding social capital (compared to lower levels) corresponds to a lower rate of contagion, ceteris paribus for NPIs, and the same correspondence is found for a higher level of bridging social capital (compared to a lower level). This further result suggests that there is a role played by social capital in incentivizing social distancing, and hence in contributing to lowering the contagion rate.

But which of the various types of social capital contributes the most to this mechanism? By comparing the coefficients of SocCap in 4.1 with those in 4.2, and those in 4.3 with those in 4.4 , we may answer this question. The coefficients of social capital of the bonding kind (4.1 and 4.3) turn out to be higher than those of bridging social capital (4.2 and 4.4) for both of the operationalizations of this concept. This finding confirms what has already been found in the literature with reference to the Italian provinces (Alfano \& Ercolano, 2020a). Two mechanisms may lie behind this result. It could be that suspicion of people outside one's family, which is typical of communities with high levels of bonding social capital, is a factor that helps to reduce contagion rates, because suspicion of outsiders makes people from these communities more careful. Alternatively, as already highlighted, it could be that the greater importance placed on protecting the elders in a family may have influenced the behavior of communities characterized by a high stock of bonding social capital, leading to a steeper decrease in COVID-19 cases.

In sum, this analysis shows that countries characterized by higher stocks of social capital have citizens that comply more strictly with NPIs. This is especially true if said countries are endowed with bonding social capital.

\section{Conclusions}

The COVID-19 pandemic was without a doubt the major event of 2020, and probably one that will be remembered for a very long time. About two years after the beginning of the global crisis, it is still not clear whether we are finally emerging from it, or simply experiencing another seasonal pause, as many countries did in the summer of 2020. Unfortunately, according to many researchers, we are destined 
to face pandemics more and more frequently in the future (Adamson et al., 2021; Hotez, 2021; Simpson et al., 2020). For these reasons, research focused on the effectiveness of policies of a non-pharmaceutical nature aimed at reducing the spread of viruses is of the utmost importance, and among the most relevant, topical and important contributions that social sciences may offer to the scientific community.

Of course, political culture plays an important role in this discontinuity, and more specifically on how citizens have reacted to this important change in their perception and everyday life. While there have been previous attempts to highlight certain characteristics of political culture that may have played a role in this relationship (Alfano \& Ercolano, 2020a; Bargain \& Aminjonov, 2020; Borgonovi \& Andrieu, 2020), to the best of our knowledge this is the first attempt to do so while taking into account both a cross-country perspective and different dimensions of the multifaceted and complex concept of social capital. Our findings show that countries with higher social capital comply more fully with NPIs, especially if they are endowed with bonding social capital.

The findings presented seem to be important for a number of stakeholders. First, the role that stocks of social capital as a whole play in this relationship highlights that this form of capital plays once again a very important role, confirmed also in this context. Perhaps more importantly, the confirmation of the finding of Alfano and Ercolano (2020a) about the greater importance in a wider, cross-country context of bonding social capital compared to bridging social capital highlights the importance of this kind of social capital, which has possibly been disregarded too often and remembered only for the role it plays in the creation of the "moral basis of a backward society" (Banfield, 1958).

In conclusion, the present research highlights once again the importance of social capital for the enforcement of successful policies. The literature has already highlighted the importance of government quality in enforcing NPIs (Alfano \& Ercolano, 2021b). The central role played by social capital revealed in this work (especially of the bonding kind), suggests that this characteristic must also be taken seriously into account when designing an NPI, or more generally a policy that is difficult to enforce, if its implementation is to be achieved successfully.

Although it expands the literature and previous findings, the present analysis has some limitations and strengths that warrant attention. First, the sample of countries analyzed is not the result of a sampling operation of a bigger population, and since it is derived from the availability of data, this may have somehow affected the results. We nonetheless believe that the countries we have been able to include in the regressions represent an important part of the European continent. Indeed, the sample includes both countries in the EU (16 out of 30, or 53.33\%) and those outside the Union; both very populous countries (such as France and Germany) and smaller ones (such as Switzerland and Albania); and finally countries that have adopted different strategies to fight COVID-19, at least during the first wave of the crisis (such as Italy and Sweden).

A second limitation is due to the reporting of COVID-19 cases, which is not a perfect operationalization of the effective number of cases that each country has seen. Indeed, these data are gathered from a number of national sources, and are of course a function of several decisions taken at the national level, such as the testing 
policy, the quality of the tests used, the number of asymptomatic cases, and so on. While we recognize that this may cause some biases in the analysis, and consider it important to warn the reader about this shortcoming, at the same time it is difficult to imagine any other way to proxy the spread of COVID-19, or possible solutions for these limitations.

On the other hand, the main strengths of this study are twofold. The first is that this research compares results from a large number of countries. This implies that our finding has a greater external validity than single-nation studies, and is more easily generalizable and applicable to new cases.

Second, the use of positive cases as our main dependent variable, while affected by the limitations that have already been discussed, has the benefit of also delivering information about the behavior followed in private places, and the attention paid to the precautions necessary to avoid contagion apart from mobility. While mobility obviously plays a very important role in spreading contagion, given that we must live with the virus for a long time, and given the necessity of producing and restoring certain habits, precautions, such as the use of masks, are very important to avoid contagion, even when mobility is reduced.

Moreover, it is important to recall that, to the best of our knowledge, this is the first attempt to perform such an analysis while taking into account both a crosscountry perspective and different dimensions of the multi-faceted and complex concept of social capital.

Future studies may be devoted to extending these findings to a different geographic region or a wider set of countries, exploiting data from other surveys.

\section{References}

Adamson, C. S., Chibale, K., Goss, R. J. M., Jaspars, M., Newman, D. J., \& Dorrington, R. A. (2021). Antiviral drug discovery: Preparing for the next pandemic. Chemical Society Review, 50(6), 36473655. https://doi.org/10.1039/D0CS01118E

Adler, P. S., \& Kwon, S. W. (2002). Social capital: Prospects for a new concept. The Academy of Management Review, 27, 17-40.

Alfano, V., Cicatiello, L., \& Ercolano, S. (2021). School openings and the COVID-19 outbreak in Italy. A provincial-level analysis using the synthetic control method. Health Policy.

Alfano, V., \& Ercolano, S. (2020a). Capitale sociale bonding e bridging alla prova del lockdown. Un'analisi sulle regioni italiane. Rivista Economica del Mezzogiorno, 3.

Alfano, V., \& Ercolano, S. (2020b). The efficacy of lockdown against COVID-19: A cross-country panel analysis. Applied Health Economics and Health Policy, 18, 509-517.

Alfano, V., \& Ercolano, S. (2020c). In fila per tre. Apertura delle scuole e seconda ondata di COVID 19. Economia e Politica, 12(2).

Alfano, V., \& Ercolano, S. (2021a). Stay at home! Governance quality and effectiveness of lockdown. Social Indicator Research.

Alfano, V., \& Ercolano, S. (2021b). Social capital, quality of institutions and lockdown. Evidence from Italian provinces. Structural Changes and Economic Dynamics, 59, 31-41.

Alfano, V., \& Sgobbi, M. (2021). A Peste, Fame et Bello libera Nos, Domine. An analysis of the black death in Chioggia in 1630. Journal of Family History.

Allison, P. D. (2009). Fixed effects regression models. Sage.

Antonietti, R., \& Boschma, R. (2018). Social capital, resilience and regional diversification in Italian regions. Available at https://econpapers.repec.org/paper/eguwpaper/1804.htm. Accessed 25 March 2021. 
Baltagi, B. H. (2008). Econometric analysis of panel data (4th ed.). Wiley.

Banfield, E. C. (1958). The moral basis of a backward society. Free Press.

Bargain, O., \& Aminjonov, U. (2020). Trust and compliance to public health policies in time of COVID19. Journal of Public Economics.

Beugelsdijk, S., \& Smulders, S. (2009). Bonding and bridging social capital and economic growth. CentER Discussion Paper, 2009-27. Tilburg University.

Bjørnskov, C. (2007). Determinants of generalized trust: A cross-country comparison. Public Choice, 130, 1-21. https://doi.org/10.1007/s11127-006-9069-1

Bogliacino, F., Codagnone, C., Montealegre, F., et al. (2021). Negative shocks predict change in cognitive function and preferences: Assessing the negative affect and stress hypothesis. Science Reports, 11, 3546. https://doi.org/10.1038/s41598-021-83089-0

Borgonovi, F., \& Andrieu, E. (2020). Bowling together by bowling alone: Social capital and COVID-19. Social Science \&amp; Medicine, 265, 113501.

Boschma, R. A. (2005). Social capital and regional development: An empirical analysis of the third Italy. In R. A. Boschma \& R. C. Kloosterman (Eds.), Learning from clusters (Vol. 80, pp. 139-168). Springer.

Bourdieu, P. (1980). Le Capital Social. Actes de la Recherche En Science Sociale, 31, 2-3.

Bourdieu, P. (1986). The forms of capital. In J. G. Richardson (Ed.), Handbook of theory and research for the sociology of education (pp. 241-258). Greenwood Press.

Bürcher, S., \& Mayer, H. (2018). Are there differences in social capital related to corporate regional engagement in dynamic and less dynamic non-core regions? European Planning Studies, 26(2), 342-364.

Centers for Disease Control and Prevention (U.S.) (2007). Interim pre-pandemic planning guidance: Community strategy for pandemic influenza mitigation in the United States: Early, targeted, layered use of nonpharmaceutical interventions.

Chan, H. F., Brumpton, M., Macintyre, A., Arapoc, J., Savage, D. A., Skali, A., \& Torgler, B. (2020). How confidence in health care systems affects mobility and compliance during the COVID-19 pandemic. PloS One, 15(10), e0240644.

Codagnone, C., Bogliacino, F., Gómez, C., et al. (2021). Restarting "normal" life after Covid-19 and the lockdown: Evidence from Spain, the United Kingdom, and Italy. Social Indicators Research, 158, 241-265.

Coleman, J. S. (1988). Social capital in the creation of human capital. The American Journal of Sociology, 94, 95-120.

Coleman, J. S. (1990). Foundations of social theory. Harvard University Press.

Cortinovis, N., Xiao, J., Boschma, R., et al. (2017). Quality of government and social capital as drivers of regional diversification in Europe. Journal of Economic Geography, 17(6), 1179-1208.

Crescenzi, R., \& Gagliardi, L. (2015). Social capital and the innovative performance of italian provinces. In C. Francesco \& Q. Francesco (Eds.), The economics of knowledge, innovation and systemic technology Policy (pp. 188-218). Routledge.

Crescenzi, R., Gagliardi, L., \& Percoco, M. (2013). The 'bright'side of social capital: How 'bridging'makes Italian provinces more innovative. In R. Crescenzi \& M. Percoco (Eds.), Geography, institutions and regional economic performance (pp. 143-164). Springer.

Degli Antoni, G., \& Grimalda, G. (2016). Groups and trust: Experimental evidence on the Olson and Putnam hypotheses. Journal of Behavioral and Experimental Economics, 61, 38-54.

EVS. (2020). European Values Study 2017: Integrated Dataset (EVS2017). GESIS Data Archive, Cologne. ZA7500 Data file Version 4.0.0. https://doi.org/10.4232/1.13560.

Farole, T., Rodriguez-Pose, A., \& Storper, M. (2011). Human geography and the institutions that underlie economic growth. Progress in Human Geography, 35(1), 58-80.

Ferragina, E. (2009). The never-ending debate about The moral basis of a backward society: Banfield and 'amoral familism.' Journal of Anthropological Society of Oxford, 1(2), 141-160.

Ferragina, E. (2010). Social capital and equality: Tocqueville's legacy: Rethinking social capital in relation with income inequalities. The Tocqueville Review/La Revue Tocqueville, The Tocqueville Society/University of Toronto Press, 31(1), 73-98.

Ferragina, E. (2011). Il fantasma di Banfield: Una verifica empirica della teoria del familismo amorale. Stato e Mercato, 2, 283-312.

Ferragina, E., \& Arrigoni, A. (2016). The rise and fall of social capital: Requiem for a theory? Political Studies Review, 15(3), 355-367.

Fine, B. (2002). Social capital versus social theory. London: Routledge. 
Granovetter, M. S. (1973). The strength of weak ties. The American Journal of Sociology, 78(6), $1360-1380$

Halaby, C. N. (2004). Panel models in sociological research: Theory into practice. Annual Review of Sociology, 30, 507-544.

Hale, T., Angrist, N., Cameron Blake, E., Hallas, L., Kira, B., Majumdar, S., Petherick, A., Phillips, T., Tatlow, H., \& Webster, S. (2020a). Variation in government responses to COVID-19 version 7.0. Blavatnik School of Government Working Paper. May 25, 2020. Available: www.bsg.ox.ac.uk/covid tracker.

Hale, T., Angrist, N., Cameron Blake, E., Hallas, L., Kira, B., Majumdar, S., Petherick, A., Phillips, T., Tatlow, H., \& Webster, S. (2020b). Oxford COVID-19 government response tracker. Blavatnik School of Government. www.bsg.ox.ac.uk/covidtracker.

Hanifan, L. (1916). The rural school community center. Annals of the American Academy of Political Science, 67, 130-138.

Hawdon, J. (2008). Legitimacy, trust, social capital, and policing styles: A theoretical statement. Police Quarterly, 11(2), 182-201.

Haynes, P. (2009). Before going any further with social capital: Eight key criticisms to address (INGENIO WORKING PAPER SERIES).

Helliwell, J. F. (2002). How's life? Combining individual and national variables to explain subjective well-being. Economic Modelling, 20,331-360.

Hotez, P. J. (2021). Preventing the next pandemic: Vaccine diplomacy in a time of anti-science. Johns Hopkins University Press.

Jacobs, J. (1961). The death and life of great American cities. Cape.

Jasanoff, S., \& Kim, S.-H. (2009). Containing the atom: Sociotechnical imaginaries and nuclear power in the United States and South Korea. Minerva, 47, 119-146.

Jones, A., Rice, N., d'Uva, T. B., \& Balia, S. (2007). Applied health economics. Routledge.

Kawachi, I., \& Berkman, L. (2001). Social ties and mental health. Journal of Urban Health, 78, 458-467.

Kawachi, I., Kennedy, B. P., \& Glass, R. (1999). Social capital and self-rated health: A contextual analysis. American Journal of Public Health, 89(8), 1187-1193.

Kawashi, I., Kennedy, B. P., Lochner, K., \& Prothrow-Stith, D. (1997). Social capital, social inequality, and mortality. American Journal of Public Health, 87(9), 1491-1498.

Kim, E. S. (2011). Policy types and regulation culture of the precautionary principle: A case study of South Korean GM-risk policy. Conference for Korean Association of Governmental Studies. Korean Association of Governmental Studies.

Knack, S. (2003). Groups, growth and trust: Cross-country evidence on the Olson and Putnam hypotheses. Public Choice, 117(3), 341-355.

Knack, S., \& Keefer, P. (1997). Does social capital have an economic payoff? A cross-country investigation. The Quarterly Journal of Economics, 62, 1251-1288.

Lauer, S. A., Grantz, K. H., Bi, Q., Jones, F. K., Zheng, Q., Meredith, H., Azman, A. S., Reich, N. G., \& Lessler, J. (2020). The incubation period of coronavirus disease 2019 (COVID-19) from publicly reported confirmed cases: Estimation and application. Annals of Internal Medicine, 2020(172), 577-582.

McShane, C. J., Turnour, J., Thompson, M., Dale, A., Prideaux, B., \& Atkinson, M. (2016). Connections: The contribution of social capital to regional development. Rural Society, 25(2), 154-169.

Muringani, J., Fitjar, R. D., \& Rodriguez-Pose, A. (2021). Social capital and economic growth in the regions of Europe. Papers in Evolutionary Economic Geography (PEEG) 2108, Utrecht University.

Neuhaus, J. M., \& Kalbfleisch, J. D. (1998). Between- and within-cluster covariate effects in the analysis of clustered data. Biometrics, 54, 638-645.

Olson, M. (1982). Stagflation and the political economy of the decline in productivity. The American Economic Review, 72(2), 143-148.

Penninx, B. W. J. H., van Tilburg, T. G., Kriegsman, D. M. W., Boeke, A. J. P., Deeg, D. J. H., \& van Eijk, J. T. M. (1999). Social networks, social support, and loneliness in older persons with different chronic diseases. Journal of Aging Health, 11, 151-168.

Poder, T. G. (2011). What is really social capital? A critical review. The American Sociologist, 42(4), $341-367$.

Putnam, R. D. (1993). Making democracy work: Civic traditions in modern Italy. Princeton University Press.

Putnam, R. D. (1995). Bowling alone: America's declining social capital. Journal of Democracy, 6, 65-78. 
Putnam, R. D. (2000). Bowling alone. The collapse and revival of American community. Simon \& Schuster.

Rabe-Hesketh, S., \& Skrondal, A. (2008). Multilevel and Longitudinal Modeling Using Stata (2nd ed.). Stata Press.

Raudenbush, S. (1989). "Centering” predictors in multilevel analysis: Choices and consequences. Multilevel Modelling Newsletter, 1(2), 10-12.

Rodriguez-Pose, A., \& Storper, M. (2006). Better rules or stronger communities? On the social foundations of institutional change and its economic effects. Economic Geography, 82(1), 1-25.

Rose, R. (2000). How much does social capital add to individual health? A survey study of Russians. Social Science \& Medicine, 51(9), 1421-1435.

Sabatini, F. (2008). Social capital and the quality of economic development. Kyklos, 61(3), 466-499.

Schunck, R. (2013). Within and between estimates in random-effects models: Advantages and drawbacks of correlated random effects and hybrid models. Stata Journal, 13(1), 65-76.

Simpson, S., Kaufmann, M. C., Glozman, V., \& Chakrabarti, A. (2020). Disease X: Accelerating the development of medical countermeasures for the next pandemic. The Lancet Infectious Diseases, 20(5), 108-115. https://doi.org/10.1016/S1473-3099(20)30123-7

Smith, A. J., Fitchett, J. M., Engelbrecht, F. A., Scholes, R. J., Dzhivhuho, G., \& Sweijd, N. A. (2020). Winter is coming: A southern hemisphere perspective of the environmental drivers of SARS-CoV-2 and the potential seasonality of COVID-19. International Journal of Environmental Research and Public Health, 17(16), 5634. https://doi.org/10.3390/ijerph17165634

Storper, M. (2005). Society, community, and economic development. Studies in Comparative International Development, 39(4), 30-57.

Storper, M. (2013). Keys to the city: How economics, institutions, social interaction, and politics shape development. Princeton University Press.

Tyler, T. R., \& Jackson, J. (2014). Popular legitimacy and the exercise of legal authority: Motivating compliance, cooperation, and engagement. Psychology, Public Policy, and Law, 20(1), 78-95.

Wollebaek, D., \& Selle, P. (2002). Does participation in voluntary associations contribute to social capital? The impact of intensity, scope, and type. Nonprofit and Voluntary Sector Quarterly, 31(1), 32-61.

Wooldridge, J. M. (2010). Econometric analysis of cross section and panel data (2nd ed.). MIT Press.

Publisher's Note Springer Nature remains neutral with regard to jurisdictional claims in published maps and institutional affiliations. 